\title{
Is it Proper to Assess Pulmonary Functions from Chest Measurements?
}

\author{
Dr Gagneen Kaur Sandhu', Dr Avnish Kumar ${ }^{2}$
}

\begin{abstract}
This study attempted to correlate chest expansion with pulmonary function values. Height, weight, biacromial breadth and chest expansion at 2 sites, axilla $(A) \&$ xiphoid $(X)$ were measured in 59 male \& 48 female medical students in the age group of 17 to 21 years. Pulmonary functions were measured using a computerized spirometer. A significant positive correlation between FVC, FEV 0.5 , FEV1, FEF25\%, FEF50\% and biacromial breadth was seen in males whereas a significant positive correlation between FVC, FEF25\%, FEF50\% and unexpanded (UE) as well as expanded (E) chest measurements in males was inferred from the observations. A significant positive correlation between PEFR \& biacromial breadth as well as expanded \& unexpanded chest measurements was evident in females. FEF 25\%-75\%, the most sensitive parameter indicating early airway obstruction has no correlation with chest expansion in both males \& females. These results prove the need to review the practice of depending upon routine chest measurements as a determinant of lung function.
\end{abstract}

Keywords: Chest expansion, Lung functions, Spirometer

\section{Introduction}

Since years lung function tests are being used for diagnosis, assessment and clinical management of breathlessness, as epidemiological and research tools and in the industrial and preventive medicine. Spirometry is a simple non-invasive method of assessing lung function. The values of pulmonary function tests are influenced by anthropometric, environmental, genetic, ethnic, socio-economic and technological variations. It is invaluable as a screening test to identify patients with airflow obstruction and is also of special importance in monitoring disease progression, response to treatment and in rating disability due to occupational hazards. Even today during medical examination for admissions in various courses \& in recruitment into service, chest expansion measurements are being routinely used to assess lung functioning. The purpose of the present study was to assess the accuracy of measuring the lung functions by using chest measurements in comparison with the lung functions determined by Spirometer.

\section{Material and Methods}

In the present study 59 male and 48 female medical students of Govt. Medical College, Patiala, were studied. All the students were in the age group of 17 years to 21 years. Students with disease or any kind of respiratory infection were excluded from the study. Age, height and weight were recorded in years (Yrs), centimeters (Cms) and kilograms (Kgs) respectively. Weight was recorded on standard regularly calibrated weighing machine. Height was recorded against a wall with a calibrated tape, in standing position with feet apposed and; the head and the body touching the wall. Both height and weight were taken without shoes. The chest circumference measurements were taken at two levels - upper and lower levels of chest. The upper level chest measurements were taken at level of posterior Axillary (A) fold and the lower chest measurements were taken at the level of tip of Xiphoid (X) process, using a calibrated measuring tape. This was the measure of the unexpanded (UE) chest. The fully expanded (E) chest was measured following deep inspiration when the subject had inspired maximally. Biacromial breadth (shoulder breadth / biacromial diameter) was measured using anthropometric rod by measuring the distance between two most lateral points on lateral margin of acromial process, in the subject standing straight with the arms hanging by his sides. Ventilatory tests were measured with a computerized Spirometer "Medspiror". Volume detection was done by pneumotach sensor and flow detection by volume differential method by the spirometer itself. Gas volumes and flows were corrected to B.T.P.S. (Body Temperature, Ambient Pressure and Saturated with Water Vapours) automatically by the instrument only. All the spirometeric lung function tests were also carried out in the standing posture. To measure the vital capacity by spirometer, the subject was asked to inspire maximally and placed a mouth piece firmly in mouth and perform maximum expiration through that mouth piece. To measure the maximum ventilatory volume (MVV), the subject was asked to breathe as rapidly and deeply as possible in and out from the mouth piece. MVV test was run for twelve seconds. Best of the three spirometeric readings of lung function parameters was recorded. The data was analyzed on PC by SPSS/PC+ version 14.0

\section{Results and Discussion}

Table 1 shows the mean values of age, height, weight, vital capacity, flow rates and chest measurements in the subjects. Simple correlation coefficient of different pulmonary function parameters and its significance with chest measurements in male subjects is shown in Table 2(a) and simple correlation coefficient of different pulmonary function parameters and its significance with chest measurements in female subjects is shown in Table 2(b). 
International Journal of Science and Research (IJSR)

ISSN (Online): 2319-7064

Index Copernicus Value (2013): 6.14 | Impact Factor (2015): 6.391

Table 1

\begin{tabular}{|c|c|c|}
\hline & $\begin{array}{c}\text { MALES } \\
\text { MEAN } \pm \text { S.D. }\end{array}$ & $\begin{array}{l}\text { FEMALES } \\
\text { MEAN } \pm \text { S.D. }\end{array}$ \\
\hline AGE (Yrs) & $18.23 \pm 0.93$ & $18.05 \pm 0.98$ \\
\hline HEIGHT (Cms) & $172.28 \pm 6.13$ & $155.58 \pm 3.69$ \\
\hline WEIGHT (Kgs) & $68.36 \pm 13.7$ & $54.82 \pm 8.39$ \\
\hline CHEST UE(A) (Cms) & $88.75 \pm 9.5$ & $82.98 \pm 6.1$ \\
\hline CHEST E (A) (Cms) & $93.47 \pm 9.53$ & $88.34 \pm 6.1$ \\
\hline CHEST UE(X) (Cms) & $82.32 \pm 8.89$ & $70.03 \pm 7.29$ \\
\hline CHEST E(X) (Cms) & $87.6 \pm 8.46$ & $75.13 \pm 7.87$ \\
\hline BIACROMIAL BREADTH (Cms) & $43.1 \pm 3.76$ & $35.48 \pm 2.13$ \\
\hline FVC (Ltrs) & $4.24 \pm 0.43$ & $2.53 \pm 0.34$ \\
\hline $\mathrm{FEV}_{0.5}$ (Ltrs) & $3.02 \pm 0.42$ & $1.66 \pm 0.57$ \\
\hline $\mathrm{FEV}_{1}$ (Ltrs) & $3.94 \pm 0.48$ & $2.36 \pm 0.33$ \\
\hline PEFR (Ltrs/Sec) & $10.47 \pm 3.0$ & $6.11 \pm 1.02$ \\
\hline $\mathrm{FEF}_{25 \%-75 \%}(\mathrm{Ltrs} / \mathrm{Sec})$ & $7.46 \pm 1.27$ & $3.18 \pm 0.66$ \\
\hline $\mathrm{FEF}_{25 \%}(\mathrm{Ltrs} / \mathrm{Sec})$ & $10.43 \pm 3.94$ & $5.44 \pm 1.10$ \\
\hline $\mathrm{FEF}_{50 \%}(\mathrm{Ltrs} / \mathrm{Sec})$ & $8.52 \pm 2.0$ & $3.56 \pm 0.80$ \\
\hline $\mathrm{FEF}_{75 \%}(\mathrm{Ltrs} / \mathrm{Sec})$ & $4.71 \pm 1.09$ & $1.86 \pm 0.49$ \\
\hline $\mathrm{FEV}_{1} / \mathrm{FVC} \%$ & $93.29 \pm 7.03$ & $92.92 \pm 6.73$ \\
\hline MVV(Ltrs/Min) & $146.26 \pm 24.2$ & $86.9 \pm 16.7$ \\
\hline
\end{tabular}

Table 2(a): Co-Efficient of Corelation " $r$ " of different pulmonary function parameters \& its significance with chest measurements in males

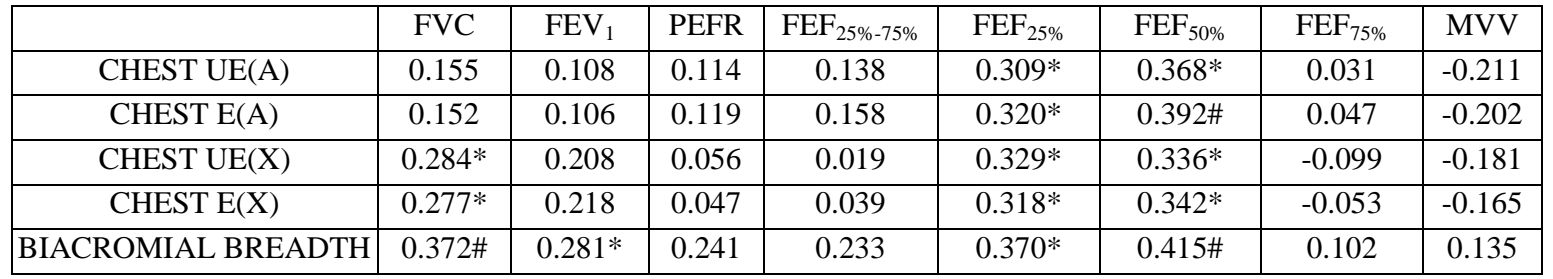

Table 2(b): Co-Efficent Of Corelation " $r$ " of different pulmonary function parameters \& its significance with chest measurements in females

\begin{tabular}{|c|c|c|c|c|c|c|c|c|}
\hline & FVC & $\mathrm{FEV}_{1}$ & PEFR & $\mathrm{FEF}_{25 \%-75 \%}$ & $\mathrm{FEF}_{25 \%}$ & $\mathrm{FEF}_{50 \%}$ & $\mathrm{FEF}_{75 \%}$ & MVV \\
\hline CHEST UE(A) & 0.113 & 0.065 & $0.343^{*}$ & 0.089 & 0.266 & 0.079 & -0.15 & 0.255 \\
\hline CHEST E(A) & 0.109 & 0.072 & $0.350^{*}$ & 0.107 & 0.270 & 0.100 & -0.007 & 0.223 \\
\hline CHEST UE(X) & -0.134 & -0.073 & $0.333^{*}$ & 0.048 & 0.151 & 0.035 & 0.001 & 0.228 \\
\hline CHEST E(X) & -0.055 & 0.036 & $0.305^{*}$ & 0.077 & 0.171 & 0.037 & 0.030 & 0.25 \\
\hline BIACROMIAL BREADTH & -0.136 & 0.024 & $0.332 *$ & 0.172 & 0.195 & 0.170 & 0.160 & 0.147 \\
\hline
\end{tabular}

* Correlation is significant at the 0.05 level

\# correlation is significant at the 0.01 level

The above observations show that in male subjects there is significant correlation between FVC (Forced Vital Capacity), $\mathrm{FEV}_{1}$ (Forced Expiratory Volume in 1 second), $\mathrm{FEF}_{25 \%}$ (Forced Expiratory Flow rate during initial 25\% of FVC), $\mathrm{FEF}_{50 \%}$ (Forced Expiratory Flow rate during 50\% of FVC) and biacromial breadth. $\mathrm{FEF}_{25 \%}$ \& $\mathrm{FEF}_{50 \%}$ also show significant correlation with expanded (E) and unexpanded (UE) chest measurements. FVC has significant correlation with values of chest expansion at xiphoid and biacromial breadth. In female subjects there is significant correlation between PEFR (Peak Expiratory Flow Rate) and biacromial breadth as well as expanded \& unexpanded chest circumference measurements at both axilla (A) and xiphoid (X). But the value of $\mathrm{FEF}_{25 \%-75 \%}$ (Forced Expiratory Flow during $25-75 \%$ of expiration) which is the most sensitive parameter indicating small airway obstruction has no correlation with chest expansion. This indicates that if the lung function assessment is done by chest measurements then the initial cases of lung impairment, where most of chronic obstructive diseases like bronchial asthma or emphysema etc start, will go unnoticed until the lung disease progresses to advanced stages of lung damage. Thus by taking the chest expansion measurements, one can only diagnose deteriorated lungs where measurable changes in chest wall circumference may be observable. Whereas with the spirometeric measurement of flow volumes and flows rates, all the lung function parameters are measured with much accuracy, leading to detection of lung dysfunction at very early stages. Similar results were reported by Pengelly (1991) and Sahin et al (2004).

\section{Volume 5 Issue 6, June 2016 www.ijsr.net}

Licensed Under Creative Commons Attribution CC BY 
This indicates that the chest expansion measurements can't be the sole criterion to interpret lung functions during medical examination for admissions in various courses $\&$ in recruitment into service, as initial stages of lung function impairment and early airway obstruction cannot be detected but only severe lung diseases. Therefore the spirometer tests are much more reliable for pulmonary function testing as even slight change in lung volume or flow rate can be easily detected with much accuracy. So in any case if chest expansion measurements are to be used for health assessment of candidates in civil services etc, then it should be used in adjunct to spirometer and surely is not a substitution.

\section{References}

[1] Cheryl M. Salome, Gregory G. King, Norbert Berend. Physiology of obesity and effects on lung function Journal of Applied Physiology Published 1 January 2010 Vol. 108 no. 1, 206-211 DOI: 10.1152/japplphysiol.00694.2009

[2] Gaensler EA. Analysis of ventilatory defect by time capacity measurements. Amer Rev Tuberc 1951;64:256278.

[3] Ganester EA. Timed Vital Capacity. Am Rev Tubercl 19511:256-278.

[4] Hermannsen J. Z Ges Exp Med 1933;90:130.

[5] Hutchinson J.On the capacity of lungs and on the respiratory functions. Med Chir Trans London 1846;29:137-232.

[6] Harpreet Ranu, Michael Wilde, and Brendan Madden. Pulmonary Function Tests.Ulster Med J. 2011 May; 80(2): 84-90.

[7] Hutchinson J. Influence of different factors on vital capacity. Med Clin Trans 1846;29-37.

[8] Pengelly CD. Are measurements of chest expansion and peak expiratory flow rate worthwhile in assessing candidates for life assurance? Br J Clin Pract. 1991 Summer;45(2):92-4.

[9] Sahin G, Ulubas B, Calikoglu M, Bolgen Cime O, Erdogan C. Is chest expansion a determinant of muscle strength in primary fibromyalgia? Joint Bone Spine.2004 Mar;71(2):140-3.

[10] Segal MS, Herschfus JA and Dulfano MJ. Dis Chest 1952;22:123.

[11] Sahin G, Guler H, Calikoglu M, Sezgin M. A comparison of respiratory muscle strength, pulmonary function tests and endurance in patients with early and late stage ankylosing spodylitis. Z Rheumatol. 2006 Oct;65(6):535-8,540. 